\title{
The Development of Innovative Multimedia through Social Lab to Promote Perception of Good Citizenship according to Democratic Values
}

\author{
Kuntida Thamwipat ${ }^{1} \&$ Pornpapatsorn Princhankol ${ }^{1}$ \\ ${ }^{1}$ Faculty of Industrial Education and Technology, King Mongkut's University of Technology Thonburi, Bangkok, \\ Thailand \\ Correspondence : Kuntida Thamwipat, Faculty of Industrial Education and Technology, King Mongkut's University of \\ Technology Thonburi, Bangkok, Thailand. E-mail: kuntida.tha@kmutt.ac.th
}

Received: August 8, 2019 Accepted: September 16, 2019 Online Published: September 25, 2019

doi:10.5539/res.v11n4p21

URL: https://doi.org/10.5539/res.v11n4p21

\begin{abstract}
This research was aimed to develop and to evaluate the quality of the innovative multimedia through social lab to promote perception of good citizenship according to democratic values, to evaluate the perception results, to evaluate the sampling group's satisfaction towards the development of innovative multimedia and to evaluate the feedback by the organizer. The sampling group in this study consisted of 2 groups. The first group was 30 state enterprise entrepreneurs from the Community under the Bridge Zone 1 at soi Pracha-Utit 76, the Community at the Back of the Suanthonburirom Park and the Community Moo 3 in the Bang Mod area. They were chosen using purposive sampling method out of those who were filmed in a short film and were willing to be models for a desk calendar and to fill out the questionnaires. The second group was 50 students from the ETM 358 Marketing Communication course and the ETM 361 Presentation Skill 2 course in the second semester of the academic year 2018. They were chosen using purposive sampling method out of those who participated in at least 2 social labs and participated in all the short film events at the cinema. The statistical methods in this research were mean score, standard deviation and feedback by the organizer. The results from the research and development were as follows:

The results from the development of the innovative multimedia through social lab to promote perception of good citizenship according to democratic values contained 3 phases with the following major media, minor media and supporting media: short film, desk calendar and facebook page, vinyl banner for publicity with QR code and events to preview the short film and to screen the film at Major Cineplex cinema at Tesco Lotus Bangpakok. The quality of the media contents as evaluated by the expert panel was at a good level $(\bar{x}=4.25$, S.D. $=0.72)$. The quality of the media presentation as evaluated by the expert panel was at a very good $(\overline{\mathrm{x}}=4.61$, S.D. $=0.32)$. The sampling group's perception of the innovative multimedia was at a high level $(\bar{x}=4.42$, S.D $=0.68)$. The sampling group's satisfaction towards the innovative multimedia was at a high level $(\bar{x}=4.36, S . D=0.72)$. These values confirmed the research hypotheses. The feedback or after action review by the learners showed that the majority had a good attitude towards service learning in conjunction with community-based learning in accordance with the research hypothesis. It was found that social work made students stronger and allowed them to think, analyze and engage in real work. They could communicate collaboratively through presentation and social media network for this course.
\end{abstract}

Keywords: innovative multimedia, social lab, perception, good citizenship, democratic values

\section{Introduction}

Scholars have defined the term "innovation" based on different viewpoints and aspects in relation to their background knowledge and professions. However, after a thorough consideration of the term there are 3 main aspects to define the features of innovation as follows:

a) Newness, that is, the thing that is created or developed as a product, service or process must be revised from the previous ones or developed from scratch (Utterback, 2004).

b) Economic benefits, that is, the commercial success of the innovation which comes from the added value of the product or the new thing. The benefits can be in the form of money or in any other forms.

c) Knowledge and Creative Idea, that is, the innovation must come from knowledge and creative idea as the basis of the new thing. It is not just an imitation or a repetition (Schilling, 2008).

The definition of the term "innovation" as given by the National Innovation Agency (NIA, 2016) is as follows: An 
innovation is a new thing which is developed out of knowledge and creativity. It gives both economic and social benefits." This is a succinct and clear definition of the term "innovation" and it can be summarized as a new thing which is created out of knowledge, experience and creative idea and it can become a new product or a new service which gives economic and social benefits.

In the past, TV channels and radio channels as well as newspapers were the main channels of information and mass media. At the present time, digital media and multimedia are playing a significant role. During the 20th century, texts and information which have been stored and broadcast in different kinds of media such as clay, tablets, radio channels, black and white TV channels as well as computers, vary greatly and they are developed to be distributed in new media in the digital age such as online radios, digital TV and the internet. It can be said that there will be a new media channel all the time. Since the beginning of the 21st century, digital media has changed the field of mass communications. Many people have used digital channels to create and broadcast their own media. Every individual can do that freely. Mass communications can no longer rely on one form of media, i.e. radios, TV channels and newspapers. Scholars in the field of mass communications, both locally and globally, have predicted that in the future digital media will have more coverage than traditional media at a significant level (Kerdwibulwet, 2016). However, multimedia is actually a combination of different kinds of media by using various materials, devices and methods in order to create the most effective and efficient way to improve learning and teaching. Each media has been used for media and now computer graphics has been added so that the presentation of the data is more engaging, thanks to images, animations and sounds. These are the core features of "Multimedia" (Malithong, 1997).

QR Code (Quick Response Code) was invented by Denso Wave Incorporated, Japan. It is a 2D barcode developed from the previous type of barcode. It can store both letters and numbers and it was aimed to provide faster and reliable process during the verification of automotive parts. Denso Wave Inc. did research and developed the barcode continuously until it was used in a commercial manner. It is convenient and effective and it can be read by scanner. It can be printed on papers and it can be applied in many situations such as education, safety, medical service, tourism, marketing and customer service (Boonrojwong and Prapraratakarta, 2017). In this research, QR codes were used to store data and to be used as links in innovative multimedia to promote perception of good citizenship according to democratic values.

According to National Education Act B.E. 2542, Chapter 4 National Education Guidelines, Section 29, educational institutions in co-operation with individuals, families, communities, community organizations, professional bodies, religious institutions, enterprises, and other social institutions shall contribute to strengthening the communities by encouraging learning in the communities themselves. Thus communities will be capable of providing education and training; searching for knowledge, data, and information; and be able to benefit from local wisdom and other sources of learning for community development in keeping with their requirements and needs; and identification of ways of promoting exchanges of development experience among communities (Ministry of Education, 1999). According to the Ninth National Economic and Social Development Plan, the provincial and regional development in accordance with national economic and social development must involve local wisdom and preservation of local culture. It must encourage the continuation of culture and arts among Thai people and to distribute the use of local wisdom in the social development. The education curriculum must be aimed to raise awareness of local wisdom and to instill the love of local land as well as to recognize the significance of traditions, culture and arts, local wisdom and Thai culture. It must encourage people to keep and to maintain Thai culture which is related to neighboring countries (The Office of the National Economic and Social Development Council, 2000).

Perception (Schiffman and Kanuk, 2000) is a process in which each individual chooses, interacts with and interprets the data in relation to stimulus in order to get a meaning and an image. Perception is a process in which people learn about their feeling and interpret external stimulus through analysis based on their memory, knowledge as well as past experience to become their understanding. In this research, the perception would be about the innovative multimedia through social lab to promote perception of good citizenship according to democratic values.

Democratic Education Center (2018) says that the main principle of democratic society is that people must participate in the national government both directly and indirectly. Reasons must be used in order to make a decision. When a decision is made through a majority vote system, it must be accepted but the minority vote must also be respected. In Thailand, after the Act of Candidate Election and the Act of Senator Selection and the decision to make 24 February 2018 to be the Election Day, (News/Thai, 2018) it has become a national topic in the early 2019, especially the topic about good citizenship according to democratic values. The main feature of good citizenship according to democratic values is that people must follow the ethics and the virtues of their religion and they must use democratic values in their life. They must obey the law to become good and useful citizens to the society. They must help one another and it will result in a real democratic society. Therefore, democratic values have become a topic for students at the Department of Educational Communications and Technology (ECT) who have knowledge and skills in the development of media and 
activities to be used in social lab. This approach was based on the belief in professionalism which Faculty of Industrial Education and Technology, King Mongkut's University of Technology Thonburi (KMUTT) promotes as the policy and one of the solutions to contribute to the 12th Strategic Plan of the University (KMUTT's 12th Strategic Plan 2017-2021, 2017). The first objective is to produce graduates who meet the required virtues as stated by KMUTT and the third objective is to develop KMUTT internationally.

The researchers have used service learning and community-based learning through the support of research and development grants from KMUTT and other external bodies to manage projects and integrate them in courses for every semester since 2012. Now there are 3 communities as in the Community under the Bridge Zone 1 at Soi Pracha-Utit 76, the Community at the Back of the Suanthonburirom Park and the Community Moo 3 in the Bang Mod area. These 3 communities have bcome social lab for the researchers and the team (Thamwipat, Princhankol and Deeyen, 2019). In the second semester of the academic year 2018, the research team integrated this Cooperative Learning approach to the ETM 358 Marketing Communication course and to the ETM 361 Presentation Skill 2 course. After the survey and the field trip to collect the opinions of the people in the communities, it was found that the people in those communities and the students were aware of the election. However, they did not know about their roles according to democratic values. Therefore, this research was done as part of social lab to develop multimedia in order to promote perception of good citizenship according to democratic values.

The researchers decided to develop innovative multimedia because of the following reasons. The Department of Educational Communications and Technology has knowledge and experience in media development and activity organization. The Faculty of Industrial Education and Technology has experience working with these 3 communities as social labs for many years. People in this generation, namely Gen Y people, are good at technology and social network because they can spend 7 hours per day on the Internet including 3 hours on social network communities (Than Settakij Newspaper, 2017). This innovative multimedia through social lab to promote perception of good citizenship according to democratic values involved community short film and calendar by Supermod. This project was aimed to develop innovative multimedia through social lab to promote perception of good citizenship according to democratic values by using the short film as the main media whereas the desk calendar and the QR codes were used as minor media to support both online and offline contents. The approach was based on service learning and community-based learning. The project covered 3 communities during the whole second semester of the academic year 2018 .

\section{Research Objectives}

1. To develop the innovative multimedia through social lab to promote perception of good citizenship according to democratic values

2. To evaluate the quality of the innovative multimedia through social lab to promote perception of good citizenship according to democratic values

3. To evaluate the perception results of the sampling group regarding the innovative multimedia through social lab to promote perception of good citizenship according to democratic values

4. To evaluate the sampling group's satisfaction towards the development of the innovative multimedia through social lab to promote perception of good citizenship according to democratic values

5. To evaluate the feedback by the organizer regarding the innovative multimedia through social lab to promote perception of good citizenship according to democratic values

\section{Research Hypothesis}

1. The innovative multimedia through social lab to promote perception of good citizenship according to democratic values would be of good quality.

2. The sampling group would have a high level of perception after the development of the innovative multimedia through social lab to promote perception of good citizenship according to democratic values.

3. The sampling group would express a high satisfaction towards the innovative multimedia through social lab to promote perception of good citizenship according to democratic values.

4. The feedback by the organizer regarding the innovative multimedia through social lab to promote perception of good citizenship according to democratic values would at a good level.

\section{Expected Outcomes}

1. There would be an innovative multimedia through social lab to promote perception of good citizenship according to democratic values.

2. This would be used as a model to develop other innovative multimedia through social lab to promote perception of 
other topics related to politics, economy, society and culture.

\section{Research Scope}

The researchers organized the event called Community Short Film and Calendar by Supermod which consisted of the development of innovative multimedia through social lab to promote perception of good citizenship according to democratic values. There would be a short film, desk calendars along with QR code technology, facebook pages, vinyl banners as well as events at Major Cineplex cinema at Tesco Lotus Bangpakok to preview and screen the short film. This was an integration in the ETM 358 Marketing Communication course and the ETM 361 Presentation Skill 2 course.

\subsection{Population}

The population in this study consisted of 2 groups.

The first group consisted of 60 state enterprise entrepreneurs from the Community under the Bridge Zone 1 at soi Pracha-Utit 76, the Community at the Back of the Suanthonburirom Park and the Community Moo 3 in the Bang Mod area ( Thamwipat, Princhankol and Deeyen, 2019).

The second group consisted of 70 students from the ETM 358 Marketing Communication course and the ETM 361 Presentation Skill 2 course in the second semester of the academic year 2018.

\subsection{Sampling Group}

The first sampling group consisted of 30 state enterprise entrepreneurs from the Community under the Bridge Zone 1 at soi Pracha-Utit 76, the Community at the Back of the Suanthonburirom Park and the Community Moo 3 in the Bang Mod area. They were chosen using purposive sampling method out of those who were filmed in the short film and were willing to be models for desk calendars and to fill out the questionnaire.

The second sampling group consisted of 50 students from the ETM 358 Marketing Communication course and the ETM 361 Presentation Skill 2 course in the second semester of the academic year 2018. They were chosen using purposive sampling method out of those who participated in at least 2 social labs and participated in all the short film events at the cinema.

\subsection{Expert Panel}

Experts are those who have knowledge, qualifications and expertise in the evaluation of the quality of the innovative multimedia through social lab to promote perception of good citizenship according to democratic values. They were chosen using purposive sampling method out of those who were qualified and willing to be in the expert panel. There were 3 experts in contents and there were 3 experts in media presentation and 3 experts who could evaluate index of congruence (IOC) of the questionnaire items. The values had to be no less than 0.50 .

\section{Research Tools}

The tools in this study were as follows:

1. The questionnaire to evaluate the quality of the innovative multimedia through social lab to promote perception of good citizenship according to democratic values

2. The questionnaire to evaluate the perception of the sampling group regarding the innovative multimedia through social lab to promote perception of good citizenship according to democratic values

3. The questionnaire to evaluate the sampling group's satisfaction towards the development of the innovative multimedia through social lab to promote perception of good citizenship according to democratic values

4. The open-ended questionnaire to evaluate the feedback by the organizer regarding the innovative multimedia through social lab to promote perception of good citizenship according to democratic values

\section{Data Analysis}

The statistical methods in this research were mean score, standard deviation and feedback or after action review by the organizer. The mean score interpretations are as follow (Srisaad, 2017)

$\begin{array}{lll}\text { mean score } 4.51-5.00 & \text { interpretation very good /highest } \\ \text { mean score } 3.51-4.50 & \text { interpretation } & \text { good/high } \\ \text { mean score } 2.51-3.50 & \text { interpretation } & \text { moderate } \\ \text { mean score } 1.51-2.50 & \text { interpretation } & \text { low } \\ \text { mean score } 1.00-1.50 & \text { interpretation } & \text { lowest }\end{array}$




\section{Research Results}

8.1 The Results From the Development of Innovative Multimedia Through Social Lab to Promote Perception of Good Citizenship According to Democratic Values

Phase 1: January to February 2019

A. Making a short film to promote democratic values through collaboration with the community (Main media)

The plot of the short film entitled "Choice" was conceived by students through their collaboration. The main idea was that "Oat was a boy who was raised by a mother so well that he never chose anything by himself. One day, he had a chance to help a disabled woman whose donation box was stolen. He felt pleased after listening to a radio program which talked about good citizenship according to democratic values. He decided to choose by himself for the first time, that is to say, he went to make a choice through his vote in an election." The film was developed by students and the cast team was students and lecturers. There were 3 locations in the film and they were the communities near the campus.

B. Making a calendar from the short film along with QR code technology to provide knowledge of good citizenship according to democratic values (Minor media)

C. Making a Facebook community for Short Film and Calendar by Supermod to promote the project and to sell calendars as well as movie tickets (Supporting media)

D. Making vinyl banners to promote the project along with QR code technology to promote the sales of calendars and movie tickets (Supporting media)
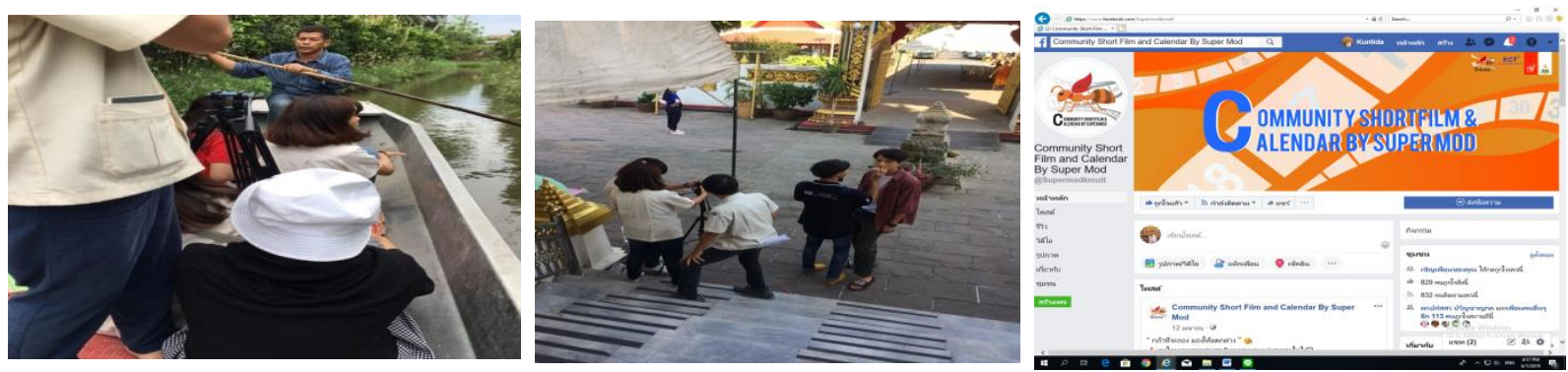

Figures show activities related to short film making
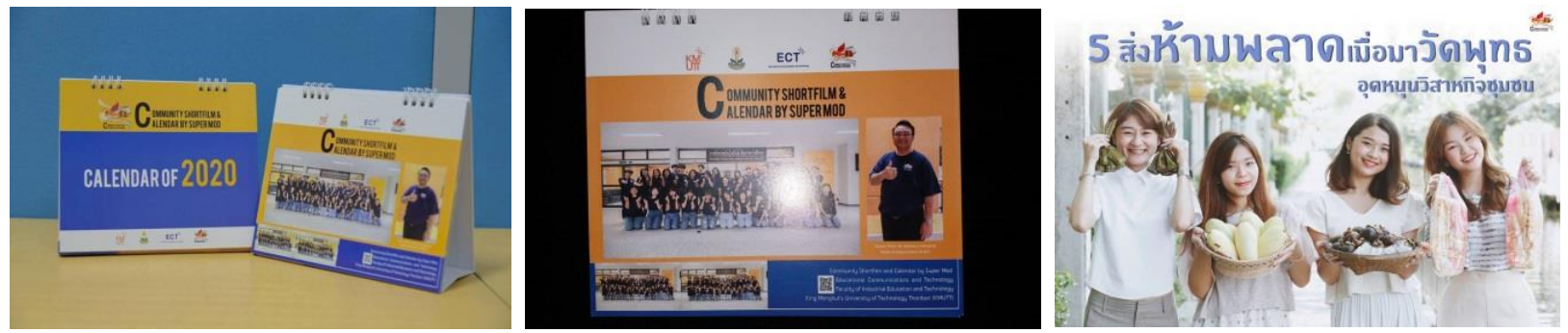

Figures show examples of innovative multimedia through social lab to promote perception of good citizenship according to democratic value 

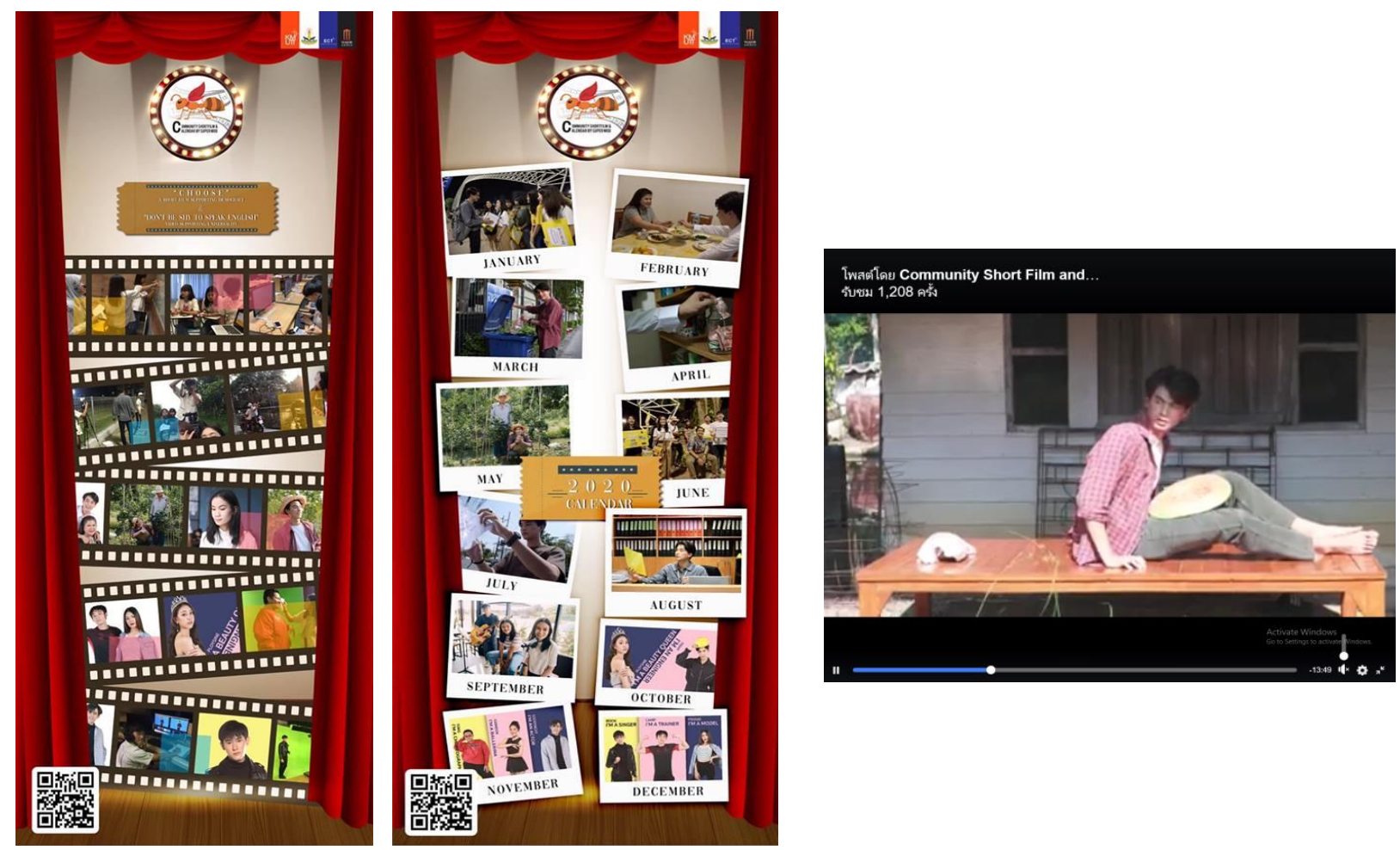

Figures show examples of innovative multimedia through social lab to promote perception of good citizenship according to democratic values

Phase 2: March to April 2019

E. Promoting, Distributing and Selling Desk Calendars from the Short Film along with QR code technology

F. Screening the short film to promote democratic values twice (Activity)

A sneak preview of the short film was given to 700 people who worked as staff members at the election booths. They attended this activity on 10 March 2019 at Meeting Hall, Faculty of Science, King Mongkut's University of Technology Thonburi.

An official screening was given to 200 people on 6 April 2019 at Major Cineplex cinema at Tesco Lotus Bangpakok. The proceeds were given to the 3 communities to be used as student scholarship, drug addict rehabilitation and co-operative funds. This was done through collaboration between third and fourth year students from two courses. They participated in these activities and were willing to offer service to these communities.
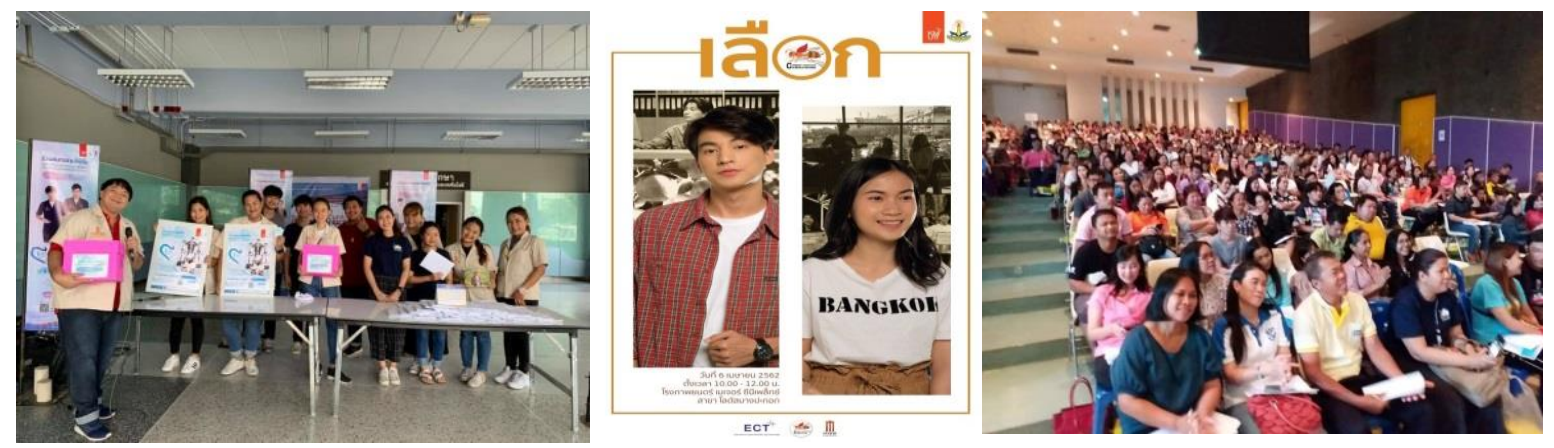

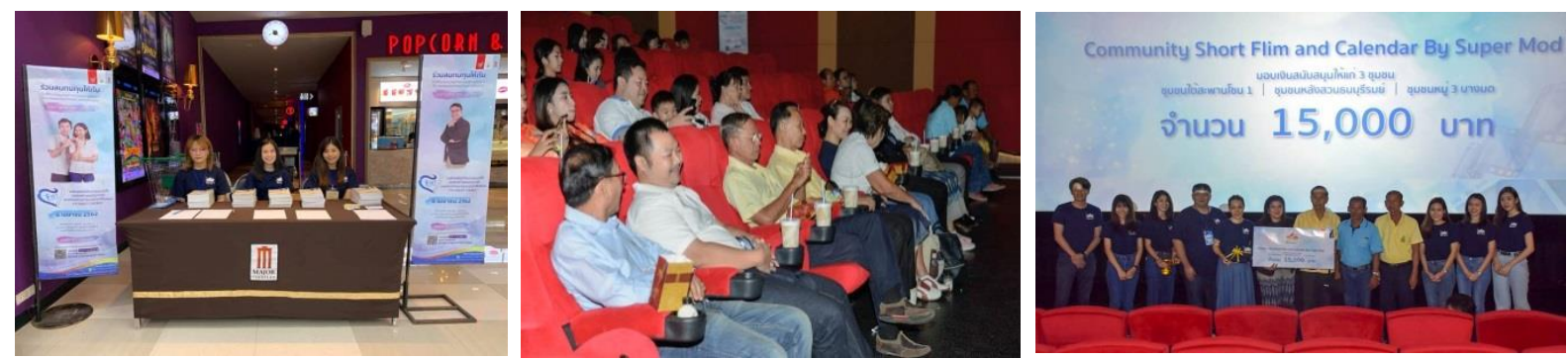

Figures show activities to promote, distribute and sell desk calendars along with QR code technology through short film during the sneak preview and the official screening

Phase 3: May 2019

G. Evaluating and feedback to conclude the project from 2 courses
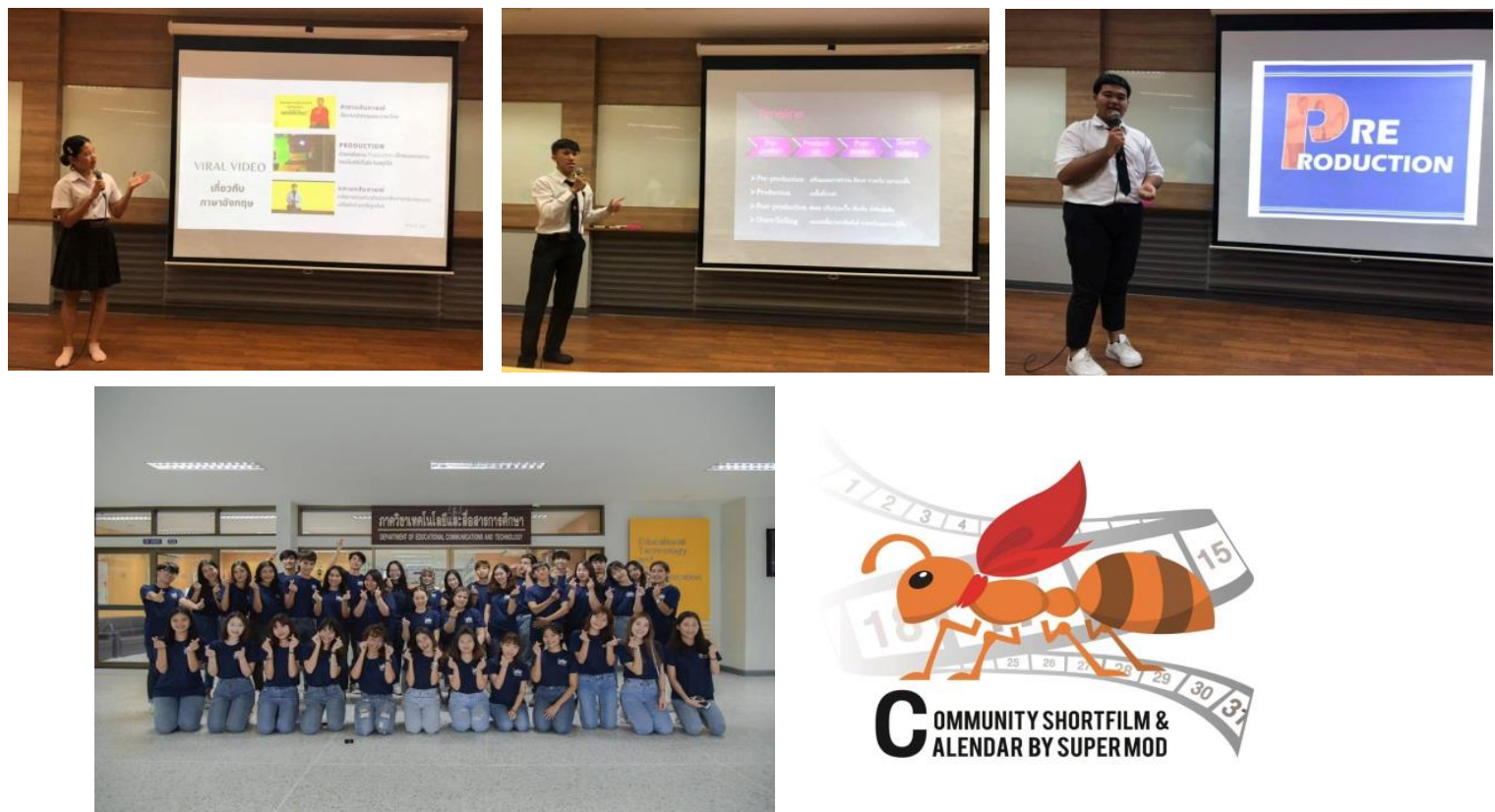

Figures show the evaluation and assessment of the project along with feedback to conclude the project.

\subsection{Results From the Evaluation of the Innovative Multimedia}

Table 1. Summarizes the results of evaluation in terms of contents and media presentation by the expert panel regarding the innovative multimedia

\begin{tabular}{l|l|l|c}
\hline Item & $\overline{\mathrm{x}}$ & S.D. & Meaning \\
\hline 1. The quality of the media contents & 4.25 & 0.72 & Good \\
\hline 2. The quality of the media presentation & 4.61 & 0.32 & Very good \\
\hline
\end{tabular}

According to Table 1, the quality of the media contents and the quality of the media presentation was at a good level and a very good level, respectively. This confirmed the research hypothesis. 


\subsection{Results From the Perception of the Innovative Multimedia}

Table 2. Summarizes the results of the sampling group's perception of the innovative multimedia

\begin{tabular}{c|c|c|c}
\hline \multicolumn{1}{c|}{ Item } & \multicolumn{3}{c}{ Result } \\
\cline { 2 - 4 } & $\overline{\mathrm{x}}$ & S.D. & Perception level \\
\hline $\begin{array}{l}\text { 1. } \begin{array}{l}\text { Being a good democratic citizen in a social } \\
\text { context }\end{array} \\
\text { 2. Being a good democratic citizen in an economic } \\
\text { context }\end{array}$ & 4.43 & 0.71 & High \\
\hline $\begin{array}{l}\text { 3. Being a good democratic citizen in a political } \\
\text { context }\end{array}$ & 4.45 & 0.72 & High \\
\hline 4. Being universal & 4.37 & 0.72 & High \\
\hline \multicolumn{1}{c}{ Total Average } & 4.42 & 0.68 & High \\
\hline
\end{tabular}

According to Table 2, the results of the sampling group's perception of the innovative multimedia through social lab to promote perception of good citizenship according to democratic values showed that their perception was at a high level $(\overline{\mathrm{x}}$ $=4.42, \mathrm{~S} . \mathrm{D}=0.68)$. This confirmed the research hypothesis.

\subsection{Results From the Sampling Group's Satisfaction Towards the Innovative Multimedia}

Table 3. Summarizes the sampling group's satisfaction towards the innovative multimedia

\begin{tabular}{|c|c|c|c|}
\hline \multirow[b]{2}{*}{ Item } & \multicolumn{3}{|c|}{ Result } \\
\hline & $\overline{\mathrm{x}}$ & S.D. & $\begin{array}{c}\text { Satisfaction } \\
\text { level }\end{array}$ \\
\hline 1. Contents & 4.40 & 0.72 & High \\
\hline 2. Format & 4.31 & 0.77 & High \\
\hline 3. Presentation & 4.37 & 0.75 & High \\
\hline Total Average & 4.36 & 0.72 & High \\
\hline
\end{tabular}

According to Table 3, the results from the sampling group's satisfaction towards the innovative multimedia showed that the sampling group's satisfaction towards the innovative multimedia through social lab to promote perception of good citizenship according to democratic values was at a high level $(\bar{x}=4.36, S . D=0.72)$. This confirmed the research hypothesis.

\subsection{Results From the Feedback or After Action Review by the Organizers Regarding the Innovative Multimedia}

The results from the feedback or after action review given by learners were at a high level. This confirmed the research hypothesis. It was found that the majority of the learners expressed a good attitude towards Service Learning and Community-Based Learning. Participation in these activities helped them in many ways. They had to think, analyze, do and engage in Participatory Communication, solve the problem, and develop both the communities and themselves after listening to their problems. They might not be able to do everything correct the first time but with guidance and supervision by the fourth year students and their friends, these students could finish the project successfully through sharing ideas and team work. After the project, they saw their progress and their change in a better direction. They would use Participatory Communication in their work and in their future.

The short film entitled "Choice" is the main media developed by the students and the cast members were also students. The main actor had worked in a TV series before and there was 1 disabled woman as well as lecturers in the film. The location of the short film was from 3 communities around the campus which participated in the social lab.

In addition, there was a desk calendar project and the calendar was related to the short film entitled "Choice" along with QR code technology. There was Facebook page for Community Short Film and Calendar by Super Mod and there were vinyl banners to promote the project along with QR code technology. There were events to promote the sales of calendars and movie tickets. The film was screened twice. The sneak preview was screened at the university and the official screening was at Major Cineplex Cinema. These were innovative multimedia through social lab to promote perception of good citizenship according to democratic values. The students were from 2 courses. So, they were from 2 different years. After the screening, the short film was uploaded online on Youtube and on the Facebook page of the project. This was to 
use innovative technology to promote the media to a wider audience so that they could watch it anywhere and anytime. The short film was also uploaded to FIETTUBE and distributed on public relations screens through digital signage of the Faculty of Industrial Education and Technology so that people on campus who had not watched it before could watch it later. This was also to promote the contents of the film, in other words, the perception of good citizenship according to democratic values, which involved everybody from students, lecturers and staff members. Service Learning and Community-Based Learning, Co-operative Learning and Participatory Communication played a major role in these 2 courses. After the evaluation, it was found that the students expressed a high satisfaction towards such instructional approach and that there was an output of high impact. The department aimed to extend this approach to other courses by applying the good practice from this project.

According to the project results and the feedback by learners, the innovative multimedia helped learners in the following ways:

A. Main media or the short film entitled "Choice"

The students learned about good citizenship according to democratic values in order to create a plot, write a screenplay and direct a film based on democratic values and Participatory Communication all through the project. (They brainstormed, gathered data, designed and shared their pride in the Service Learning and Community-Based Learning).

The communities participated in the selection of location for the film and the products of the communities so that they could learn about good citizenship according to democratic values.

B. Minor media or 500 sets of desk calendars from the short film entitled "Choice" along with QR code technology

Buyers could learn about good citizenship according to democratic values from the images and texts which were printed in the calendar.

C. Supporting media or the Facebook page with 1,100 likes and 2 vinyl banners to promote the activities along with QR code technology

Students participated in their collaboration to work between junior and senior students with lecturers as mediators and viewers. (There were 900 people who watched the screening. There were 1,200 views on Youtube and it was shared 30 times.) They learned about the contents from the short film and they learned from the minor media or the desk calendar from the short film.

The communities learned to use their budget wisely. The organizers gave each community 5,000 Baht from the proceeds after the screening and the sales of desk calendars. The community under the bridge zone 1 used this money to build a center for drug addict rehabilitation. The community behind Suan Thonburirom used to this money to give scholarship to poor students who did well at school. The community Moo 3 Bang Mod used the money to finance the co-operative funds. These activities were what each community wanted and they had a high level of satisfaction.

\section{Research Discussions}

The results from the development of innovative multimedia through social lab to promote perception of good citizenship according to democratic values were good because the project followed the ADDIE Model (Anukulwet, 2014) which consists of 5 steps as in Analysis, Design, Development, Implementation and Evaluation. Analysis involved a study and analysis of data from reliable sources and setting a clear objective and a target group. Design was about using the data to design innovative multimedia after the analysis. Development involved the expert panel who evaluated the quality of contents and media presentation of the innovative multimedia. Then, the researchers considered their feedback and revised the contents according to the feedback. Implementation involved the sampling group who watched the innovative multimedia and evaluated their perception as well as their satisfaction. Evaluation involved data collection, in other words, the data from the sampling group was analyzed using statistical methods. The development of innovative multimedia through social lab to promote perception of good citizenship according to democratic values was part of sustainable develop project which contained 3 parts as follows (Open Development Thailand, 2018):

A. Strategies to apply philosophy of sufficiency economy to achieve a national goal

B. Projects to cover activities and events during the timeframe

C. Follow-ups to apply index of work in accordance with UN index and other indices

Philosophy of sufficiency economy, which many organizations are working, on will be useful for the success of 17 targets of the National Sustainable Development Project B.E. 2560. Thailand ranked 55th out of 157 countries in the index in order to help each country to check their ranking in terms of sufficiency economy practices. Thailand has made a lot of investment to fight against poverty (Target 1) and to make sure that people get clean water as well as healthcare (Target 6). Still, more attempts need to be made in order to help Thailand succeed in achieving these targets. There must 
be more collaboration so that the development becomes significant. King Mongkut's University of Technology Thonburi (KMUTT) is an autonomous public university and one of the missions is to provide academic service to the community (KMUTT for SDG2030, 2019) in order to build strength to the communities through bodies of knowledge by both faculty and students. Research and development are the right solution to those problems.

According to the results from the evaluation of the quality in terms of contents by the expert panel, the quality was at a good level $(\overline{\mathrm{x}}=4.25$, S.D. $=0.72)$. The results from the evaluation of the quality in terms of media presentation was at a very good level $(\bar{x}=4.61$, S.D. $=0.32)$. The sampling group's satisfaction towards the innovative multimedia was at a high level $(\bar{x}=4.36, S . D=0.72)$. These confirmed the research hypotheses and complied with the research study by Longpradit, Suebdode, Saksipornchai, Thamwipat and Princhankol (2016) who conducted a study into the development of advertising media and CSR activities to present a short documentary to support the learning funds and vocational development, King Mongkut's University of Technology Thonburi. Their research results showed that the quality of the media and activities in terms of contents was at a good level $(\bar{x}=4.71$, S.D. $=0.31)$. The quality of the media presentation was at a very good level $(\overrightarrow{\mathrm{x}}=4.53$, S.D. $=0.50)$. The sampling group' s satisfaction was at a high level $(\overrightarrow{\mathrm{x}}=$ 4.49,S.D. = 0.49). It can be concluded that the advertising media and CSR activities to present a short documentary can be used with the target group. Regarding the perception, it was at a high level $(\overline{\mathrm{x}}=4.42, \mathrm{~S} . \mathrm{D}=0.68)$. This confirmed the research hypothesis in accordance with the research study by Panitcharoenpol (2013) who conducted a study into the development of electronic book entitled "Information Technology and Communications" for Mathayomsuksa 1 students in junior high schools under the supervision of High School Commission Zone 17 in Trad Province. The perception level was at a high level $(\overline{\mathrm{x}}=4.06$, S.D. $=0.75)$.

The feedback by learners showed that the majority of the students expressed a good attitude towards Service Learning and Community-Based Learning. Participation in these activities helped them in many ways. They had to think, analyze, do and engage in Participatory Communication. This was similar to the research study by Thamwipat and Yookong (2012) who conducted the analysis of the components of Project-Based Learning on social network with a case study of presentation skill course. It was found that there were 10 components and that there were 3 steps of Project-Based Learning in accordance with the Department of Curriculum and Instruction Development Ministry of Education. The 3 steps were as follows: 1) Activities before Project consisted of the following components: introducing presentation skills, sharing opinions through online social networks, preparing learners before the project, planning as well as developing skills, and presentation skills based on individuals and groups. 2) Activities during Project consisted of the following components: sharing responsibilities during the project work and communication, procedure by the individuals or groups through online social network, introducing regulations and conditions for learners. 3) Activities after Project consisted of managing files and documents, presentation, evaluation by lecturers, giving feedback and congratulations to presenters, as well as evaluation from multiple channels. The regression or predictive equation of the components of Project-Based Learning on social network was as follows: $\mathrm{Y}=780$ (Factor 1) + . 603(Factor 2) + . $686($ Factor 3$)+.591($ Factor 4$)+.741($ Factor 5$)+.912($ Factor 6$)+.632($ Factor 7$)+.824($ Factor 8$)+.689($ Factor 9$)$ +.686 (Factor 10). The total variance accounted for $60 \%$ and the deviation was 10.00 . The instructors used Active Learning approach and used different methods of evaluation in the research. In this research study, the feedback was used in order to give suggestions and open-ended questions were used on the Facebook group so that everybody could share their message independently.

\section{Suggestions}

\subsection{Suggestions From the Research Results}

- The results from the research showed that the audience of the innovative multimedia through social lab to promote perception of good citizenship according to democratic values had a high level of perception because the contents and the format of the media presentation were approved by the expert panel. There were many revisions. Moreover, there was a survey on the communities and the opinion of the students. Therefore, each party had a wide scope of perception.

- The results from the evaluation of feedback by learners showed that the majority of students had a good attitude towards Service Learning and Community-Based learning. Participation in these activities helped them in many ways. They had to think, analyze, do and engage in Participatory Communication, solve the problem, and develop both the communities and themselves after listening to their problems. This active learning approach to instruction is a good example which other courses in the department can adopt to develop learning for students in the future.

\subsection{Suggestions for Further Research}

- There should be a study into the analysis of components of service learning and community-based learning through social lab to achieve the sustainable development. 
- There should be a project about the dissemination of knowledge of online marketing communication for state enterprise.

\section{Acknowledgements}

The researchers would like to extend our gratitude towards the Department of Educational Communications and Technology, Faculty of Industrial Education and Techonology, King Mongkut's University of Technology Thonburi for funding the project about the vision development. We also appreciate the support by 3 communities around campus for their participation in social lab and Major Cineplex Cinema.

\section{References}

Anukulwet, A. (2014). ADDIE MODEL. [Online], Available: http://lms.thaicyberu.go.th/ [Retrieved 26 September 2018].

Boonrojwong, N., \& Prapraratakarta, K. (2017). Different types of QR Codes. Association of Private Higher Education Institutions of Thailand under the Patronage of Her Royal Highness Princess Maha Chakri Sirindhorn, 6(1).

Democratic Education Center. (2018). Principles of Democratic Government. [Online], Available: https://www.ect.go.th/dec/ewt_news.php?nid=71\&filename=index [Retrieved 23 November 2018].

Kerdwibulwet, C. (2016). New Digital Media: New Media of the Future. National Institute of Development Administration (NIDA) Press. Bangkok.

King Mongkut's University of Technology Thonburi. (2017). The 12th Strategic Goals (2017-2021). Bangkok: Prikwan Graphic Company.

KMUTT for SDG2030. (2019). Sustainable Development Goals. [Online]. Retrieved from http://sustainable.kmutt.ac.th/sustainability/?q=content/sustainable-development-goals/

Longpradit, K., Suebdode, S., Saksipornchai, P., Thamwipat, K., \& Princhankol, P. (2016). The Development of Advertising Media and CSR Activities to Present a Short Documentary to Support the Learning Funds and Vocational Development, King Mongkut's University of Technology Thonburi. Conference on Innovation for Community Health, KX Building, King Mongkut's University of Technology Thonburi, 15-16 December 2016.

Malithong, G. (1997). Innovative Educational Technology. Bangkok: Chulalongkorn University Press.

Ministry of Education. (1999). National Education Act B.E. 2542 (1999). Bangkok: Kurusapa Printing Press.

National Innovation Agency. (2016). Top Innovations of Thailand. Bangkok: National Innovation Agency, Ministry of Science and Technology.

News/Thai. (2018). Election Day. [Online]. Retrieved from https://www.bbc.com/thai/thailand-45493498

Office of the National Economic and Social Development Council. (2000). The 9th Vision and Direction of the Development. Bangkok.

Open Development Thailand. (2018). Sustainable Development Goals. [Online], Available: https://thailand.opendevelopmentmekong.net/th/topics/sustainable-development-goals/, [Retrieved 8 June 2019].

Panitcharoenpol, O. (2013). The Development of Electronic Book Entitled "Information Technology and Communications" for Mathayomsuksa 1 Students in Junior High Schools under the Supervision of High School Commission Zone 17 in Trad Province. Master's thesis in Curriculum and Instruction. Rambhai Barni Rajabhat University, Chantaburi.

Schiffman, \& Kanuk. (2000). Customer Behavior - Psychology Aspects. New Jersey: Prentice-Hall.

Schilling, M. A. (2008). Strategic Management of Technological Innovation (2nd ed.). NY: McGraw-Hill Education.

Srisaad, B. (2017). Fundamental Research. Bangkok: Suweerayasarn Company Limited.

Thamwipat, K., \& Yookong, N. (2012). The Analysis of the Components of Project-Based Learning on Social Network: A Case Study of Presentation Skill Course. International Journal of Advanced Computer Science and Applications, 3(11), 2012. https://doi.org/10.14569/IJACSA.2012.031132

Thamwipat, K., Princhankol, P., \& Deeyen, N. (2019). The Development of Multimedia and Activities to Promote Products Made by State Enterprise Communities in the Bangmod Project 4.0 through Community-Based Learning. International Education Studies, 12(4). https://doi.org/10.5539/ies.v12n4p49

Than Settakij Newspaper. (2017). Gen Y Population: Behaviors for Opportunities and Risks. 37(3), 23-25, November 2017. 
Uejirpong, S. et al. (2010). Innovation: Meaning. Type and Significance for Entrepreneurs. Journal of Business Administration. Thammasat University, 33(128), October to December 2010. https://doi.org/10.3138/uram.33.1-2.128

Utterback, J. M. (2004). The Dynamics of Innovation. Educause Review, 39(1).

\section{Copyrights}

Copyright for this article is retained by the author(s), with first publication rights granted to the journal.

This is an open-access article distributed under the terms and conditions of the Creative Commons Attribution license (http://creativecommons.org/licenses/by/4.0/). 